Strategies for Promoting Strong Inferences in Political Psychology Research Anthony N. Washburn

Linda J. Skitka

University of Illinois at Chicago

Chapter prepared for B. T. Rutjens \& M. J. Brandt (Eds.), Belief systems and the perception of reality. 


\section{Strategies for Promoting Strong Inferences in Political Psychology Research}

Professor X grew up in the rural countryside and had a long-standing belief that country living was healthier than living in an urban setting. She decided that this might be a decent area of inquiry, and so developed a theory explaining why rural upbringings are especially wholesome compared to urban upbringings, and set out to conduct research to confirm her hypothesis. Professor X examined differences in crime exposure, safety, violence, etc., between rural and urban settings to test her theory. All her findings collected over a very long career in fact revealed evidence that there are many positives to growing up in rural as compared to urban settings. Should the question of where to raise wholesome children therefore be considered settled science?

There are at least two reasons why the answer to this question is "no." First, Professor X relied on positive test strategies, that is, she only tested the benefits, but not the possible harms or costs of rural as compared to urban living. Second, Professor X focused on hypothesis confirmation to the neglect of falsification. For example, she only considered contexts where rural upbringing would perform better than urban upbringing (e.g., exposure to crime) without considering contexts where urban upbringing might perform better than rural upbringing (e.g., exposure to greater diversity) — that is, contexts that would be more likely to falsify her theory.

The same problems emerge when one tests hypotheses about ideological differences using a constrained set of stimuli and with a goal to confirm rather than provide a strong test of a hypothesis. Someone might have the hypothesis, for example, that conservatives are more prejudiced than liberals, and tests this hypothesis by examining whether there are ideological differences in racial animus, only to confirm her hypothesis. Does this mean a tendency toward prejudice is hard baked into conservative thinking? Without testing the same hypothesis using a 
wider variety of possible targets of prejudice with the explicit goal of possible hypothesis disconfirmation we cannot be certain. Strong inferences require testing hypotheses not only in the contexts most favorable for hypothesis confirmation, but in the contexts most favorable for hypothesis disconfirmation as well (Platt, 1964).

The goals of this chapter are to first describe two common pitfalls of social psychological approaches to the study of ideological differences, specifically, a pre-occupation with explaining conservatives to the neglect of liberals and an over-reliance on positive test strategies. As guards against these potential pit falls, we recommend that researchers shift their orientation toward negative test strategies, something that can be facilitated by using a "grid" approach to hypothesis generation. The grid approach to hypothesis generation forces researchers to consider a set of competing explanations for liberal and conservative thoughts, feelings, and behavior, that vary in possible normative spin, which helps protect against possible researcher bias. Before turning to the specifics of the grid approach and providing examples of it in action, we first review these common pitfalls in this area of research that the grid approach is designed to address.

\section{A One-sided Coin}

Social and political psychology have tended to focus on a single side of the "ideological coin," without fully appreciating that a more complete description of the coin would emerge if both sides were considered in concert. In other words, social and political psychology has been in the business of "explaining” conservatism for years (e.g., Jost, Glaser, Kruglanski, \& Sulloway, 2003), starting with a focus on the authoritarian personality (e.g., Adorno, FrenkelBrunswick, Levinson, \& Sanford, 1950; Frenkel-Brunswick, 1949) something that eventually morphed into a focus on explaining right-leaning political beliefs more generally (e.g., 
Altemeyer, 1981). The dominant problem to be explained seemed to be that conservatives were "different" or non-normative, an orientation that remained relatively unchallenged until recently (e.g., Brandt, Reyna, Chambers, Crawford, \& Wetherell, 2014; Conway et al., 2015; Frimer, Skitka, \& Motyl, 2017; Morgan, Mullen, \& Skitka, 2010).

One reason for the focus on explaining conservatism to the relative neglect of liberalism may be that the field is liberally biased (e.g., Duarte et al., 2015). Consistent with this idea, the ratio of liberal to conservative professors in psychology has been conservatively estimated to be about 11:1 (Rothman \& Lichter, 2008). The ideological imbalance of researchers in psychology, particularly in social psychology, has the potential to undermine the integrity of psychological research by allowing liberal values to become embedded into theories and methods (Duarte et al., 2015). Social psychologists may concentrate on research topics or tests that confirm liberal narratives and avoid topics that contradict or challenge their biases. Due to lack of ideological diversity, liberal values and positions manifest as the norm, and conservative values and positions become the deviation that needs to be explained. Outside of a massive influx of conservative graduate students or faculty into the field, social psychologists who study ideological differences need to become aware of these biases to rule out their influence in the scientific process (see Mullen, Bauman, \& Skitka, 2003; Tetlock, 1994; Washburn, Morgan, \& Skitka, 2015 for other discussions of these issues).

\section{An Over-reliance on Positive Test Strategies to Test Ideological Differences}

Compounding the issues of one-sided thinking and ideological homogeneity in social psychology, is the tendency for researchers to rely on positive test strategies when testing for ideological differences. Positive test strategies occur when researchers test hypotheses by examining situations in which the hypothesized effect should occur if true or by examining 
instances in which differences are known to have occurred to see if the hypothesized conditions prevail (e.g., Klayman \& Ha, 1987). In other words, researchers often design studies with the goal of confirming a given hypothesis, rather than with the goal of testing its falsifiability. Compounding this problem, is the natural human bias to believe evidence that is consistent with one's hypotheses is more likely to represent "truth" (specifically, confirmation bias, Kunda, 1990). Therefore, positive test strategies are focused on hypothesis confirmation, rather than hypothesis testing, and researchers are likely to be biased toward accepting conclusions congenial with their own preconceptions.

A related issue is a bias toward discovering differences rather than similarities. Similar to how people think of themselves as more extraverted when asked specifically about extraversion (as compared to introversion) (e.g., Sanitioso, Kunda, \& Fong, 1990), researchers who specifically (and exclusively) ask about how liberals and conservatives are different will be more likely to find evidence supporting differences without ever giving proper vetting to the idea of ideological similarity. Because ideological differences are often hypothesized, claims of ideological similarity have often relied on interpreting null results, a practice discouraged in the world of null-hypothesis significance testing (e.g., Cohen, 1994). Alternatively, researchers could take a strong inferences approach to testing ideological differences where one designs crucial experiments that test mutually incompatible hypotheses under conditions that allow for hypothesis elimination rather than hypothesis confirmation (e.g., McGuire, 2004; Platt, 1964); in other words, they could use both positive and negative test strategies.

\section{The Grid Approach to Hypothesis Testing}

One approach to developing competing, rather than confirmatory, hypotheses is to take a grid approach to hypothesis construction. The grid approach to hypothesis confirmation uses 
both positive and negative testing strategies to develop competing hypotheses for ideological differences and similarities than can be tested in one research program. The grid approach also borrows heavily from perspectivism, or the idea that all hypotheses can be both true and false depending on one's perspective and taking into account potential moderators (see McGuire, 2004 for a review). We detail each aspect of the grid approach in turn.

Using negative test strategies. One way to avoid the potential pitfalls of positive testing strategies in political psychology is to consider ideological differences in terms of moderators, or conditions when one might expect to find evidence of ideological similarities versus differences for one psychological construct or another. A negative testing strategy is when one hypothesizes the exact opposite of one's preferred hypothesis, and tests this alternative hypothesis under conditions that should be maximally amenable to confirming it. For example, common hypotheses in political psychology are that conservatives are more prejudiced and intolerant (e.g., Sibley \& Duckitt, 2008) and are more obedient to and respectful of authorities than liberals (e.g., Altemeyer, 2004; Graham, Haidt, \& Nosek, 2009; Pratto, Sidanius, Stallworth, \& Malle, 1994). Although these predictions were based on sound theoretical rationales, the results of these studies were nonetheless products of positive test strategies because the conditions for testing differences in intolerance and prejudice were especially conducive to finding that conservatives were higher on these traits than liberals.

More recent research on ideological differences in prejudice, intolerance, and authority obedience, however, have generated competing hypotheses and designed studies to allow for the possibility of arriving at the exact opposite conclusion (e.g., liberals are more intolerant, etc., e.g., Brandt et al., 2014; Frimer, Gaucher, \& Schaefer, 2014). This research found that yes, conservatives are more prejudiced against groups that pose perceived threats to cherished 
conservative values (e.g., racial or sexual minorities). But liberals express similar levels of prejudice and discrimination against groups that violate their cherished values (e.g., pro-life advocates and Tea Party supporters, Brandt et al., 2014). Additionally, liberals and conservatives both have positive views about obeying authorities, once one takes into account whether the authority is generally perceived as a more liberal or conservative one (Frimer et al., 2014). Both groups are positive about obeying authorities that they see as representing their respective values. The moderator of ideological effects on intolerance and obedience is the type of group one is being intolerant of or obedient towards. Of course, the type of group is undoubtedly not the sole moderator of the relationship between ideology and these psychological outcomes, but manipulating the target group allows for researchers to explicitly test competing hypotheses rather than confirm one set of hypotheses or one direction of hypotheses.

Using perspectivism to develop competing hypotheses. Perspectivism argues that one can generate possible conditions where a given hypothesis should be true and should be false. For example, exposure to television violence may increase or decrease violent behavior for different theoretical reasons (e.g., McGuire, 2004). Exposure to television violence may legitimize violent behavior by portraying it as acceptable, thus leading to increase violent behavior (e.g., Berkowitz, Corwin, \& Heironimus, 1963). Alternatively, television violence exposure may reduce violent behavior because watching television violence provides a cathartic release for aggressive individuals (e.g., Feshbach \& Singer, 1971). A perspectivist orientation requires designing studies that allow one to test competing hypotheses for any given phenomena. The grid approach builds on the strong inference goal of testing competing hypotheses by recommending that researchers also test flattering and unflattering explanations for any given 
phenomena (cf. Tetlock \& Mitchel, 1993). In short, researchers are recommended to generate hypotheses using a 2 X 2 grid (see Figure 1).

Constructing the grid. The grid approach to hypothesis construction starts with posing an initial research question about ideology. For example, the initial question might focus on conservatives, such as "Why are conservatives less willing than liberals to want to help the poor or personally responsible?" Then, using a hypothesis-generation strategy of accounting for the contrary of a hypothesis (McGuire, 1997), the goal is to reverse the focus of the initial research statement to explain liberals, rather than conservatives. This simply involves replacing liberals for conservatives as the subject of the research question, such as, "Why are liberals more willing than conservatives to want to help the poor and personally responsible?" Specifically laying out research questions that implicate both sides of the political spectrum allows one to develop more balanced theoretical explanations and hypothesis tests. This strategy ensures that researchers think equally hard about the psychology of both conservatives and liberals.

The grid approach to hypothesis construction intentionally guides the researcher to also develop more and less flattering explanations for politicized research questions as a protection against bias. In other words, researchers should come up with at least two possible hypotheses when posing questions about why liberals and conservatives might differ - an explanation that is normatively more flattering and unflattering for each group (see Figure 1 for an example). When one interacts the dual-sided research question with more and less flattering explanations, a 2 X 2 grid emerges that forces the researcher to test equally plausible hypotheses for why liberals' or conservatives' behavior is consistent with a normatively more or less flattering explanation.

The grid in action. The grid approach might be most easily understood if we provide a concrete example of it in use, as we have hinted in our example questions above - that is, by 
generating theoretically plausible competing explanations for why there are ideological differences in willingness to help people personally responsible for their plight, even when there are sufficient resources to help everyone (Skitka \& Tetlock, 1992), that also vary in normative valence. Skitka and Tetlock (1993) provides a useful example.

Explaining conservatives' unwillingness to help the personally responsible. The goal of the grid approach, again, is to generate equally plausible theoretical explanations for conservatives' unwillingness to help that vary in normative implication. Toward this end, Skitka and Tetlock (1993) posited that one reason why conservatives are less willing than liberals to help the poor or personally responsible is that they want to punish people who failed to take sufficient care of themselves. The punitiveness hypothesis suggests that conservatives respond angrily to claimants seeking public assistance for problems for which they are personally responsible because conservatives are more motivated than liberals to punish violators of traditional values and norms of hard work and self-reliance. If this rather unflattering characterization of conservative motivation is true, anger and hostility should mediate the relationship between ideology and willingness to help those personally responsible for their plight.

A more flattering explanation for the same behavior, however, might be that conservatives are not acting in a blind rage, but instead might be dispassionately applying principles of learning theory (e.g., McClelland, 1987). Instead of responding with anger to claims of need by those responsible for their plight, conservatives might dispassionately withhold assistance because a properly functioning society depends on enforcing certain social norms and avoiding a slippery slope, and because of a need to model to others that there are consequences for misbehavior (e.g., Jencks, 1992; Murray, 1984). If the deterrence hypothesis is true, anger 
should not mediate the relationship between ideology and willingness to help. Moreover, ideological differences in willingness to help the responsible should disappear if the personally responsible show credible evidence of reform.

Explaining liberals' willingness to help the personally responsible. The next step in the grid approach is to develop explanations for liberals' behavior, rather than focusing exclusively on explanations for conservatives' behavior in this context. In other words, how can we explain why liberals tend to help those personally responsible for their quandary? One possible explanation might be that liberals want to avoid making difficult decisions or trade-offs or to think too carefully about why people need help. From a cognitive effort perspective, making equal allocations to claimants regardless of why they need help is much simpler than carefully scrutinizing each claim, and developing a mental algorithm of what counts as deserving versus undeserving need (e.g., Kahneman, 2003; Langer, 1978; Stanovich \& West, 2000). If the mindlessness hypothesis is true, liberals should be more likely to fail to notice a mistaken "extra" person on a "who to help" checklist than will conservatives, and liberals should allocate resources more like conservatives when they are forced to think carefully about why people need help.

A more flattering interpretation of liberals' willingness to help might be that liberals are effortfully down-regulating negative reactions to those personally responsible to their plight. In other words, liberals and conservatives might be equally likely to feel initial distaste toward those who refuse to help themselves. Liberals' commitment to humanitarianism and egalitarianism, however, may create a sense of dissonance that will lead them to check a more automatic tendency to make person-centered attributions for behavior and to feel anger or distaste, and to generate some sympathy instead. If this motivated correction hypothesis is true, 
liberals should only be more likely than conservatives to help the personally responsible when they have sufficient cognitive resources to engage in down regulation of anger and disgust, and the up regulation of sympathy instead.

Testing the grid. After fleshing out comparatively flattering and unflattering hypotheses for observed ideological differences in willingness to help the personally responsible, the next step is to develop a set of studies that test each of these competing hypotheses (something that is unlikely to be possible in a single study). Skitka and Tetlock (1993) found that negative affect did mediate the relationship between conservativism and willingness to help those personally responsible for their plight. However, conservatives were just as willing to help reformed claimants as they were willing to help those who were not responsible for their plight. In other words, conservatives were not merely seeking to punish free-riders, but were carefully considering the potential future repercussions of providing assistance to those who might not use the money wisely. They also found that liberals were not mindlessly egalitarian but instead considered the tradeoffs between spending resources wisely and helping those in need. When the suffering or need outweighed the goal of the resource allocation, liberals were more likely to provide assistance than not. In short, Skitka and Tetlock (1993) found stronger support for the motivated correction explanation for liberals' willingness to help (and no support for the mindlessness hypothesis), and for the deterrence explanation for conservatives' comparative unwillingness to help (and no support for the punitiveness hypothesis). Examining "both sides of the coin"- more positively and negatively valenced explanations for both liberals' and conservatives' behavior-provided a more complete understanding of the cognitive and motivational underpinnings of ideological differences. 
Studying different explanations for ideological differences in willingness to help the personally responsible, however, is not the only research context in which a grid approach helps to advance knowledge. We turn next to an application of the grid approach to generating alternative hypotheses for understanding prejudice.

Applying the grid to ideological prejudice. As mentioned in the beginning of this chapter, theorists in political and social psychology have tended to argue that conservatives tend to be more prejudiced and discriminatory than liberals (see Sibley \& Duckitt, 2008 for a metaanalysis). However, much of the research on this "prejudice gap" has focused on explaining why conservatives are more prejudiced than liberals, and not also trying to explain why liberals appear to be less prejudiced toward the same groups. Chambers, Schlenker, and Collisson (2013), however, was an exception, and approached this research topic from a strong inferences perspective by testing competing and ideologically balanced hypotheses. Although they did not explicitly construct their hypotheses in the grid format, we can easily adapt their theoretical rationales and study designs to see how their approach fit this strong inferences format, and therefore avoided the pitfalls outlined at the beginning of this chapter.

Explaining conservatives' prejudice toward low-status groups. The goal of the grid approach, again, is to generate equally plausible theoretical explanations for conservatives' prejudice that vary in normative implication. Chambers et al. (2013) theorized that one reason why conservatives are more prejudiced toward low-status groups than liberals is that conservatives are motivated to justify social hierarchies and are threatened by groups that might desire social change (i.e., low-status groups like African Americans, Kay \& Jost, 2003; Sidanius \& Pratto, 2001). The system justification/social dominance hypothesis perspective suggests that conservatives, more than liberals, are motivated to see the social system as fair and, therefore, 
legitimize differences between high and low status groups. Because low-status groups often seek social change to better their circumstances, conservatives react to them with fear and hostility because these groups potentially threaten conservatives' social status. If the system justification hypothesis is true, conservatives should be similarly prejudiced toward all low-status groups, regardless of their perceived political affiliation (e.g., liberal and conservative African Americans).

A more flattering explanation for the same prejudiced behavior, however, might be that conservatives are not threatened by groups who seek social change because it threatens conservatives' status, but instead might be prejudiced toward groups that threaten important conservative values (e.g., Chambers \& Melnyk, 2006; Henry \& Reyna, 2007). Instead of harboring negative feelings toward all low-status groups, conservatives may only be prejudiced against groups they perceive as violating their ideological values. Because many low-status groups tend to be liberal or at least support liberal policies that go against conservative values (e.g., ethnic minority groups often support social welfare programs and affirmative action), conservatives may only appear to be irrationally prejudiced toward low-status groups when, in fact, they are defending their ideological worldviews from perceived threats. If the (perhaps somewhat more flattering) selective prejudice hypothesis is true, conservatives should only show prejudice toward low-status groups that are perceived to be ideological worldview threats (e.g., obviously liberal African Americans), rather than show prejudice to all low-status groups (e.g., obviously conservative African Americans) (see Figure 2).

Explaining liberals' positive regard toward low-status groups. Chambers et al. (2013) also theorized that liberals might be less prejudiced toward low-status groups than conservatives because liberals value equality and are more concerned with issues of social justice and reform 
than their conservative peers (e.g., Farwell \& Weiner, 2000). Liberals might therefore be motivated to have higher esteem for low-status groups because helping these groups will facilitate a more egalitarian society (a core liberal value). If this comparatively flattering liberal egalitarian hypothesis is true, liberals should show similar positive regard toward all low-status groups, regardless of perceived political affiliation.

In contrast to the liberal egalitarian hypothesis, a relatively less flattering interpretation might be that liberals only display positive regard to low-status groups that are sympathetic to a liberal ideological worldview, and are prepared to neglect needy groups who are unlikely to advance liberals' interests. If the somewhat cynical selective positive regard hypothesis is true, liberals should only show positive regard toward low-status groups that are perceived to have similar ideological values (e.g., obviously liberal African Americans), and neglect those who do not (e.g., obviously conservative African Americans) (see Figure 2).

Testing the ideological prejudice grid. Liberal and conservative participants across three studies were asked to give impression ratings of different target groups and individuals (e.g., African Americans, Chambers et al., 2013). In support of the selective prejudice hypothesis, conservatives had less favorable impressions of a Black target when the target was portrayed as having liberal compared to conservative policy stances. Conservatives were therefore not blindly motivated to dislike any low-status group, but only disliked those whose ideological worldviews conflicted with their own. Similarly, in support of the selective positive regard hypothesis, liberals had more favorable impressions of a Black target when the target endorsed liberal policy stances compared to conservative policy stances. Liberals, therefore, were not motivated by strictly egalitarian motives to help the disadvantaged. Instead, liberals were only selectively motivated to help low-status groups whose ideological worldviews fit with their own. These 
results, along with many like them (e.g., Crawford \& Pilanski, 2014; Wetherell, Brandt, \& Reyna, 2013), suggest that motivations for conservative and liberal prejudice and intolerance are primarily driven by ideological worldview conflict, rather than one-sided ideological individual differences (e.g., conservative system justification or liberal egalitarianism).

In summary, the grid approach to hypothesis testing for ideological differences allows researchers to make strong inferences about when, why, and where liberals and conservatives behave the way that they do. Depending on context and theoretical perspective, researchers can come to vastly different conclusions about conservative and liberal behavior as a function of how they pose their research question. It is equally important to try to explain liberals' in addition to conservatives' thoughts, feelings, and behavior, and to at least attempt to balance ideological biases by making sure that one fully explores explanations that are equally likely to paint ideological motivations as normatively positive or negative. Failing this, one should at least consider positive and negative ways to frame any given finding. As the results above revealed, cynical explanations of liberals' motivations are equally as plausible as more cynical explanations for conservatives' motivations.

\section{Conclusion}

The goal of any field of inquiry is to advance knowledge. Testing hypotheses in some fields, however, are not very likely to be infected with ideological biases. Because political psychologists are themselves motivated reasoners when it comes to politicized topics, guarding against ideological bias is especially crucial to building a solid corpus of knowledge. Although many have documented actual and potential ways in which psychologists studying political issues may be biasing their research (e.g., Duarte et al., 2015; Inbar \& Lammers, 2012; Jussim, Crawford, Anglin, Stevens, \& Duarte, 2016; cf. Skitka, 2012), there is still a question of whether 
the reality of ideological bias matches possible perceptions of ideological bias in the field. The range of responses in the commentaries on Duarte et al. (2015) suggest that the match between the reality of bias and perception of bias might depend on who you ask. For example, more liberal researchers might perceive ideological bias to be less of a problem than it actually is because such bias reflects poorly on liberals. However, more conservative researchers might perceive ideological bias to be more of a problem than it actually is because a lot of the findings in social and political psychology have painted conservatives in a negative light. Regardless of which case it is, the best antidote to real or perceived bias is to design studies that conform to the grid approach — that is, research explicitly designed to consider whether there are plausible positive and negative explanations for both liberals' and conservatives' thoughts, feelings, and behaviors, and to test these possibilities using approaches that allow for strong inferences. 


\section{References}

Altemeyer, B. (1981). Right-wing authoritarianism. Winnipeg, Manitoba, Canada: University of Manitoba Press.

Altemeyer, B. (2004). Highly dominating, highly authoritarian personalities. The Journal of Social Psychology, 144(4), 421-448.

Amodio, D. M., Jost, J. T., Master, S. L., \& Yee, C. M. (2007). Neurocognitive correlates of liberalism and conservatism. Nature Neuroscience, 10, 1246-1247.

Berkowitz, L., Corwin, R., \& Heironimus, M. (1963). Film violence and subsequent aggressive tendencies. Public Opinion Quarterly, 27, 217-29.

Brandt, M. J., Reyna, C., Chambers, J. R., Crawford, J. T., \& Wetherell, G. (2014). The ideological-conflict hypothesis: Intolerance among both liberals and conservatives. Current Directions in Psychological Science, 23(1), 27-34.

Brandt, M. J., Wetherell, G., \& Reyna, C. (2014). Liberals and conservatives can show similarities in negativity bias. Behavioral and Brain Sciences, 37, 307-308.

Chambers, J. R., \& Melnyk, D. (2006). Why do I hate thee? Conflict misperceptions and intergroup mistrust. Personality and Social Psychology Bulletin, 32, 1295-1311.

Chambers, J. R., Schlenker, B. R., \& Collisson, B. (2013). Ideology and prejudice: The role of value conflicts. Psychological Science, 24, 140-149.

Cohen, J. (1994). The earth is round ( $p<.05)$. American Psychologist, 49, 997-1003.

Conway, L. G., Gornick, L. J., Houck, S. C., Anderson, C., Stockert, J., Sessoms, D., \& Mccue, K. (2015). Are conservatives really more simple-minded than liberals? The domain specificity of complex thinking. Political Psychology, 37(6), 777-798. 
Crawford, J. T., \& Pilanski, J. M. (2014). Political intolerance, right and left. Political Psychology, 35, 841-851.

Duarte, J. L., Crawford, J. T., Stern, C., Haidt, J., Jussim, L., \& Tetlock, P. E. (2015). Political diversity will improve social psychological science. Behavioral and Brain Sciences, 38, e130.

Farwell, L., \& Weiner, B. (2000). Bleeding hearts and the heartless: Popular perceptions of liberal and conservative ideologies. Personality and Social Psychology Bulletin, 26, 845852.

Feshbach, S., \& Singer, R. D. (1971). Television and aggression: An experimental field study. San Francisco, CA: Jossey-Bass.

Frenkel-Brunswik, E. (1949). Intolerance of ambiguity as emotional and perceptual personality variable. Journal of Personality, 18, 108-143.

Frimer, J. A., Gaucher, D., \& Schaefer, N. K. (2014). Political conservatives' affinity for obedience to authority is loyal, not blind. Personality and Social Psychology Bulletin, 40(9), 1205-1214.

Frimer, J. A., Skitka, L. J., \& Motyl, M. (2017). Liberals and conservatives are similarly motivated to avoid exposure to one another's opinions. Journal of Experimental Social Psychology, 72, 1-12.

Graham, J., Haidt, J., \& Nosek, B. A. (2009). Liberals and conservatives rely on different sets of moral foundations. Journal of Personality and Social Psychology, 96(5), 1029-46.

Henry, P. J., \& Reyna, C. (2007). Value judgments: The impact of perceived value violations on American political attitudes. Political Psychology, 28, 273-298. 
Inbar, Y. \& Lammers, J. (2012). Political diversity in social and political psychology. Perspectives on Psychological Science, 7, 496 - 503.

Jencks, C. (1992). Rethinking social policy: Race, poverty, and the underclass. Cambridge, MA: Harvard University Press.

Jost, J. T., Glaser, J., Kruglanski, A. W., \& Sulloway, F. J. (2003). Political conservatism as motivated social cognition. Psychological Bulletin, 129(3), 339-375.

Jussim, L., Crawford, J. T., Anglin, S. M., Stevens, S. T., \& Duarte, J. L. (2016). Interpretations and methods: Towards a more effectively self-correcting social psychology. Journal of Experimental Social Psychology, 66, 116-133.

Kahneman, D. (2003). A perspective on judgment and choice: Mapping bounded rationality. American Psychologist, 58(9), 697-720.

Kay, A. C., \& Jost, J. T. (2003). Complementary justice: Effects of "poor but happy" and "poor but honest" stereotype exemplars on system justification and implicit activation of the justice motive. Journal of Personality and Social Psychology, 85, 823-837.

Klayman, J., \& Ha, Y. W. (1987). Confirmation, disconfirmation, and information in hypothesis testing. Psychological Review, 94(2), 211-228.

Kunda, Z. (1990). The case for motivated reasoning. Psychological Bulletin, 108(3), 480-498.

Langer, E. J. (1978). Rethinking the role of thought in social interaction. In J. Harvey, W. Ickes, \& R. F. Kidd (Eds.), New directions in attribution research (Vol. 2). Hillsdale, NJ: Erlbaum.

McClelland, D. C. (1987). Human motivation. Cambridge England; New York: Cambridge University Press. 
McGuire, W. J. (1997). Creative hypothesis generating in psychology: Some useful heuristics. Annual Review of Psychology, 48, 1-30.

McGuire, W. J. (2004). A perspectivist approach to theory construction. Personality and Social Psychology Review, 8, 173-182.

Morgan, G. S., Mullen, E., \& Skitka, L. J. (2010). When values and attributions collide: Liberals' and conservatives' values motivate attributions for alleged misdeeds. Personality and Social Psychology Bulletin, 36(9), 1241-1254.

Mullen, E., Bauman, C. W., \& Skitka, L. J. (2003). Avoiding the pitfalls of a politicized psychology. Analyses of Social Issues and Public Policy, 3, 171-176.

Murray, C. (1984). Losing ground: American social policy, 1950-1980. New York: Basic Books. Platt, J. R. (1964). Strong inference. Science, 146(3642), 347-353.

Pratto, F., Sidanius, J., Stallworth, L. M., \& Malle, B. F. (1994). Social dominance orientation: A personality variable predicting social and political attitudes. Journal of Personality and Social Psychology, 67(4), 741.

Rothman, S., \& Lichter, S. R. (2008). The vanishing conservative: Is there a glass ceiling? In R. Maranto, R. E. Redding, \& F. M. Hess (Eds.), The politically correct university: Problems, scope, and reforms (pp. 60-76) Washington, D. C.: AEI Press.

Sanitioso, R., Kunda, Z., \& Fong, G. T. (1990). Motivated recruitment of autobiographical memories. Journal of Personality and Social psychology, 59(2), 229-241.

Sibley, C. G., \& Duckitt, J. (2008). Personality and prejudice: A meta-analysis and theoretical review. Personality and Social Psychology Review, 12(3), 248-279.

Sidanius, J., \& Pratto, F. (2001). Social dominance: An intergroup theory of social hierarchy and oppression. Cambridge, England: Cambridge University Press. 
Skitka, L. J. (2012). Multifaceted problems: Liberal bias and the need for scientific rigor in selfcritical research. Perspectives on Psychological Science, 7, 508-511.

Skitka, L. J., \& Tetlock, P. E. (1992). Allocating scarce resources: A contingency model of distributive justice. Journal of Experimental Social Psychology, 28, 33-37.

Skitka, L. J., \& Tetlock, P. E. (1993). Providing public assistance: Cognitive and motivational processes underlying liberal and conservative policy preferences. Journal of Personality and Social Psychology, 65(6), 1205.

Stanovich, K. E., \& West, R. F. (2000). Individual differences in reasoning: Implications for the rationality debate? Behavioral and Brain Sciences, 23(5), 645-665.

Tetlock, P. E. (1994). Political psychology of politicized psychology: Is the road to scientific hell paved with good moral intentions? Political Psychology, 15, 509-529.

Tetlock, P. E. \& Mitchell, P. G. (1993). Liberal and conservative approaches to justice: Conflicting psychological portraits. In B. Mellers \& J. Baron (Eds.), Psychological perspectives on justice. Cambridge: Cambridge University Press.

Washburn, A. N., Morgan, G. S., \& Skitka, L. J. (2015). A checklist to facilitate objective hypothesis testing in social psychology research. Behavioral and Brain Sciences, 38, e161.

Wetherell, G. A., Brandt, M. J., \& Reyna, C. (2013). Discrimination across the ideological divide: The role of perceptions of value violations and abstract values in discrimination by liberals and conservatives. Social Psychological and Personality Science, 4, 658-667. 


\begin{tabular}{|c|c|c|}
\hline & More Flattering & Less Flattering \\
\hline $\begin{array}{c}\text { Explaining } \\
\text { Conservatives }\end{array}$ & $\begin{array}{l}\text { Conservatives are } \\
\text { dispassionately applying } \\
\text { what we know about } \\
\text { learning theory: We } \\
\text { shouldn't reward } \\
\text { misbehavior [shouldn't involve } \\
\text { anger] }\end{array}$ & $\begin{array}{l}\text { Conservatives are } \\
\text { punishing people for being } \\
\text { irresponsible [should involve } \\
\text { anger] }\end{array}$ \\
\hline $\begin{array}{l}\text { Explaining } \\
\text { Liberals }\end{array}$ & $\begin{array}{l}\text { Liberals' sympathy toward } \\
\text { people who need help } \\
\text { trumps attributions of } \\
\text { responsibility in driving } \\
\text { helping decisions [should } \\
\text { require cognitive effort] }\end{array}$ & $\begin{array}{l}\text { Liberals are mindlessly } \\
\text { helping everyone instead } \\
\text { of making the tragic } \\
\text { choices needed for a well- } \\
\text { ordered society to function } \\
\text { well [effect should disappear if we } \\
\text { make them think carefully about } \\
\text { responsibility] }\end{array}$ \\
\hline
\end{tabular}

Figure 1. Example grid approach explaining ideological differences in willingness to help people personally responsible for their plight (see also Skitka \& Tetlock, 1993). Highlighted cells indicated supported hypotheses. 


\begin{tabular}{|c|c|c|}
\hline & More Flattering & Less Flattering \\
\hline $\begin{array}{c}\text { Explaining } \\
\text { Conservatives }\end{array}$ & $\begin{array}{l}\text { Conservatives are } \\
\text { prejudiced toward low- } \\
\text { status groups whose } \\
\text { values conflict with } \\
\text { conservative values (e.g., } \\
\text { liberal groups) [should only } \\
\text { apply to liberal low-status groups] }\end{array}$ & $\begin{array}{l}\text { Conservatives are } \\
\text { prejudiced toward low- } \\
\text { status groups because of } \\
\text { perceived threats to social } \\
\text { hierarchy [should apply to liberal } \\
\text { and conservative low-status groups] }\end{array}$ \\
\hline $\begin{array}{c}\text { Explaining } \\
\text { Liberals }\end{array}$ & $\begin{array}{l}\text { Liberals show positive } \\
\text { regard to low-status groups } \\
\text { because of a desire for a } \\
\text { more equal society [should } \\
\text { apply to liberal and conservative low- } \\
\text { status groups] }\end{array}$ & $\begin{array}{l}\text { Liberals selectively show } \\
\text { positive regard to low- } \\
\text { status groups whose } \\
\text { values fit with liberal values } \\
\text { (e.g., liberal groups) [should } \\
\text { only apply to liberal low-status groups] }\end{array}$ \\
\hline
\end{tabular}

Figure 2. Example grid approach explaining ideological differences in prejudice (see also

Chambers, Schlenker, \& Collisson, 2013). Highlighted cells indicated supported hypotheses. 